\title{
Correction: Mitigating losses: how scientific organisations can help address the impact of the COVID-19 pandemic on early-career researchers
}

Sandra López-Vergès, Bernardo Urbani, David Fernández Rivas, Sandeep Kaur-Ghumaan, Anna K. Coussens, Felix Moronta-Barrios (1D), Suraj Bhattarai, Leila Niamir (D), Velia Siciliano, Andreea Molnar, Amanda Weltman, Meghnath Dhimal, Shalini S. Arya, Karen J. Cloete, Almas Taj Awan, Stefan Kohler (D, Chandra Shekhar Sharma, Clarissa Rios Rojas (1), Yoko Shimpuku, John Ganle, Maryam M. Matin (1), Justine G. Nzweundji, Abdeslam Badre (1) \& Paulina Carmona-Mora (1)

Correction to: Humanities and Social Sciences Communications https://doi.org/10.1057/s41599-021-00944-1, published online 19 November 2021.

A correction has been made to the online article and PDF to ensure one of the author's affiliations was correctly listed.

The original text stated that Felix Moronta-Barrios was affiliated with:

- International Centre for Genetic Engineering and Biotechnology, Trieste, Italy.

- International Institute for Applied Systems Analysis (IIASA), Laxenburg, Austria.

This has now been corrected, so that Felix Moronta-Barrios is only affiliated with:

- International Centre for Genetic Engineering and Biotechnology, Trieste, Italy.

Published online: 02 December 2021

\footnotetext{
(c) Open Access This article is licensed under a Creative Commons Attribution 4.0 International License, which permits use, sharing, adaptation, distribution and reproduction in any medium or format, as long as you give appropriate credit to the original author(s) and the source, provide a link to the Creative Commons license,

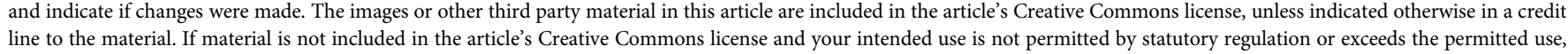
you will need to obtain permission directly from the copyright holder. To view a copy of this license, visit http://creativecommons.org/licenses/by/4.0/.
}

(c) The Author(s) 2021 